\title{
Role of non-absorbable oral antibiotics in bowel preparation for intracavitary brachytherapy: effects of rifaximin on rectal dosimetric parameters during vaginal cuff brachytherapy
}

\author{
Sasan Razmjoo, MD', Ali Bagheri, MD!, Hodjatollah Shahbazian, MD', Seyed-Mohammad Hosseini, MD', \\ Faezeh Ebrahimian-Tabrizi, MD² \\ 'Department of Clinical Oncology and Clinical Research Development Center, Golestan Hospital, Ahvaz Jundishapur University of Medical \\ Sciences, Ahvaz, Iran, ${ }^{2}$ Department of Clinical Oncology, Golestan Hospital, Ahvaz Jundishapur University of Medical Sciences, Ahvaz, Iran
}

\begin{abstract}
Purpose: Brachytherapy is a major tool for dose escalation in gynecological cancer treatment. Control of rectal repletion is particularly challenging; it can impact dose received by this organ at risk and there are reported toxicities. The use of methods, such as enema and bowel preparation, to reduce rectal volume is a difficult process for patients, and its repeatability requires patients' cooperation. Due to the effect of antibiotics on reducing intestinal gases, this study was conducted to measure the effect of adding rifaximin to bowel preparation on rectal dose-volume histogram (DVH) parameters.

Material and methods: In this prospective interventional study, 24 patients with cervical and endometrial cancer were treated with adjuvant high-dose-rate (HDR) brachytherapy. Both first and second sessions of brachytherapy were performed with bowel preparation, before and after the administration of rifaximin, respectively. The rectum was contoured as an organ at risk, and DVH parameters were recorded and compared in both sessions using magnetic resonance imaging (MRI)-based 3D treatment planning system.

Results: Rifaximin consumption reduced the rectal volume $(p=0.01)$, but had no significant correlation with other DVH parameters, especially $\mathrm{D}_{2 \mathrm{cc}}(p=0.599)$. Moreover, rectal volume had no significant correlation with DVH parameters (all $p$-values $\leq 0.05$ ).

Conclusions: Even though the addition of rifaximin to bowel preparation significantly reduced rectal volume, no significant difference was observed in DVH parameters. Therefore, it is recommended that adjuvant vaginal cuff HDR brachytherapy should be performed without the use of rifaximin, until further researches' validate its effects.

J Contemp Brachytherapy 2021; 13, 4: 426-432 DOI: https://doi.org/10.5114/jcb.2021.108597

Key words: brachytherapy, rifaximin, rectal volume, dose-volume histogram.

\section{Purpose}

Endometrial cancer is the most common gynecological cancer and the fourth most common cancer in women. Generally, the disease is seen in post-menopausal women, and the average age at diagnosis is 61 years [1-4]. Cervical cancer is the second most common cancer in women worldwide. Approximately $70 \%$ of cervical cancers occur in developing countries, and are the third leading cause of cancer deaths in women $[4,5]$. Radiation therapy with or without chemotherapy is used as an adjuvant treatment after surgery in patients with high-risk features for local and/or regional recurrences, as a definitive treatment in inoperable cases, or in patients with more advanced and/or unresectable diseases. Radiation therapy could

be prescribed as external radiotherapy, brachytherapy, or a combination of external radiotherapy and brachytherapy. Brachytherapy is a standard part of treatment of uterine and cervical cancers. The goal of adjuvant vaginal cuff brachytherapy is to deliver a high enough dose to the vaginal mucosa while sparing surrounding normal tissues and organs at risk [6-9].

Rectum is an important organ at risk (OAR) in pelvic organ brachytherapy, especially in definitive settings [6-12]. According to the American Brachytherapy Society (ABS) consensus guidelines for adjuvant vaginal cuff brachytherapy, doses at ICRU reference points for the rectum and bladder should be reported in all cases [6]. Several studies investigated rectal dose-volume histogram (DVH) parameters and verified the $\mathrm{D}_{2 \mathrm{cc}}$ (the lowest
\end{abstract}


dose received in $2 \mathrm{cc}$ of the organ volume obtaining the highest dose) of rectum as a predictive factor for longterm rectal complications. This factor provides a good estimate of the total dose of rectal wall [8-12]. In a study by Zhou et al. with 144 cervical cancer patients, there was a significant direct correlation between $\mathrm{D}_{0.1 \mathrm{cc}}, \mathrm{D}_{1 \mathrm{cc}}$ and $\mathrm{D}_{2 \mathrm{cc}}$, mainly with grade 3 and above rectal complications [8]. A study by Kato et al. showed that $\mathrm{D}_{0.1 \mathrm{cc},} \mathrm{D}_{1 \mathrm{cc}}$ and $\mathrm{D}_{2 \mathrm{cc}}$ of the rectum in cervical cancer brachytherapy were useful predictors for late rectal complications [9]. In a study on 38 patients who underwent intravaginal brachytherapy, Holloway et al. showed that $\mathrm{D}_{0.1 \mathrm{cc}}$ and $\mathrm{D}_{2 \mathrm{cc}}$ values of the bladder, rectum, and sigmoid had a significantly direct correlation with the volume of these organs at risk. Their study did not support reporting doses to the bladder and rectum after first fraction of intravaginal cylinder brachytherapy due to small within-patient dose variations [12].

Various studies have examined the effect of filling and emptying the rectum by using enema or tubes to remove gas from the rectum, with conflicting results [13-22]. In a study by Sabater et al. on 11 patients with endometrial cancer who underwent adjuvant brachytherapy after surgery, rectal volume and $D_{1 \mathrm{cc}}$ decreased up to $15 \%$ as for the rectum emptied of gas [15]. A study by Sabater et al. examined the effect of rectal filling on the received rectal dose during vaginal cuff brachytherapy, and showed that $\mathrm{D}_{\max }, \mathrm{D}_{0.1 \mathrm{cc}}, \mathrm{D}_{1 \mathrm{cc}}$ and $\mathrm{D}_{2 \mathrm{cc}}$ increased with increasing rectal volume [16]. In a study by Yahya et al. with prostate cancer patients who were candidates for radiotherapy, bowel enema significantly reduced rectal volume compared to bowel preparation with a high fiber diet or no bowel preparation [17].

Several studies have investigated effects of antibiotics in reducing the intestinal bacterial load and thus decreasing bowel gas [23-29]. Rifaximin has been used as an antibiotic without systemic absorption in various studies with good results and minimal systemic side effects [2325]. Pimentel et al. analyzed 1,260 patients with irritable bowel syndrome and showed that the rate of symptoms reduction in rifaximin group was higher than in placebo group $(40 \%$ vs. $30 \%)$, with the same side effects in both cohorts [23]. In a study, Lauritano and colleagues investigated 144 patients with intestinal bacterial overgrowth; one group received 1,200 $\mathrm{mg}$ daily of rifaximin and the other group received $750 \mathrm{mg}$ daily metronidazole. The decontamination rate of patients in the rifaximin group was significantly higher (63\% vs. $43 \%)$ and the rate of side effects was lower [24]. Di-Stefano et al. studied the effect of rifaximin in reducing intestinal gas production and compared it with active charcoal. The dose of rifaximin and charcoal was $400 \mathrm{mg}$ every 12 hours for 7 days. The amount of gas produced was obtained by respiratory $\mathrm{H}_{2}$, $\mathrm{CO}_{2}$, and $\mathrm{CH}_{4}$ measurements. Only rifaximin reduced the intestinal gas production and gas-related symptoms of patients [25].

The use of methods, such as enema and bowel preparation, to reduce rectal volume is a difficult process for patients, and its repeatability requires patients' cooperation. Due to the effect of antibiotics on reducing intestinal gas, this study was conducted to measure the effect of adding rifaximin to bowel preparation on rectal DVH parameters, especially $D_{2 c c}$ and the correlation of these parameters with each other. On the other hand, concomitant use of rifaximin in bowel preparation increases difficulty for patients as well as increases cost of the procedure. This study aimed to measure the effect of adding rifaximin to bowel preparation on rectal DVH parameters as well as to determine the effect of changes in volume parameters on each other and rectal dose parameters. If DVH parameters would improve by adding rifaximin to intestinal preparation, it could be possible to reduce the complexity and difficulty of enema and intestinal preparation, or even eliminate them in patients receiving adjuvant vaginal cuff brachytherapy. But if adding rifaximin would not result in reducing the rectal volume or dose, adjuvant vaginal cuff brachytherapy should be performed without rifaximin intake.

\section{Material and methods}

From September 2019 to March 2020, all cervical and endometrial cancer patients were referred to brachytherapy ward of Ahvaz Golestan Hospital for adjuvant highdose-rate (HDR) brachytherapy, out of which, 24 patients were enrolled into this prospective interventional study. Local ethics committee of Ahvaz Jundishapur University of Medical Sciences approved the study (IR. AJUMS. REC. 1398.714), and informed consent was obtained from every patient before the enrollment. All patients were treated with surgery (hysterectomy) with or without adjuvant pelvic radiotherapy and were candidates for adjuvant vaginal cuff brachytherapy.

Each patient received an individual total dose in a different number of sessions of brachytherapy according to pathology findings, type of surgery, and application of adjuvant pelvic radiotherapy; however, since the comparison of DVH between two sessions was sufficient, only the first two sessions of brachytherapy were recorded and analyzed. The first session of brachytherapy was performed with a bowel preparation before the administration of rifaximin. Immediately after the first session, patients received rifaximin at a dose of $400 \mathrm{mg}$ every 12 hours for 7 days, and on the $8^{\text {th }}$ day, the second session of brachytherapy was performed with a bowel preparation.

Bowel preparation was performed in all patients in such a way that the patient was only allowed to consume water, tea, coffee without milk, apple juice, colorless soft drink, completely smoothed soup, or jelly without fruit from 12 AM of the day before brachytherapy until 12 PM. At $12 \mathrm{AM}$ of the day before treatment, $10 \mathrm{mg}$ bisacodyl was administered, and at 4 PM, a tablespoon of PEG powder was dissolved in a glass of water and used; after 10 minutes, the second glass of PEG was applied. It was forbidden to eat or drink from 8 AM of the day of treatment.

All patients underwent pelvic magnetic resonance imaging (MRI) scan with a $2 \mathrm{~mm}$ slice thickness using Siemens Magnetom Essenza ${ }^{\circledR} 1.5$ Tesla MRI system. MR images were transferred into a computerized treatment planning system, and an MRI-based 3-dimensional treatment planning was performed using Eckert \& Ziegler BEBIG HDR Plus ${ }^{\circledR} 3.0 .8$ system after contouring rectum 
from rectosigmoid junction to ischial tuberosity, according to the American Brachytherapy Society (ABS) guideline.

HDR brachytherapy was administered with an Eckert \& Ziegler BEBIG Co-60 MultiSource ${ }^{\circledR}$ HDR afterloader on an outpatient basis without anesthesia. In each session, the patients received a dose of $500 \mathrm{cGy}$ to $0.5 \mathrm{~cm}$ in depth and $4 \mathrm{~cm}$ in length of vaginal mucosa using an intravaginal cylinder.

DVH parameters, including rectal volume, $\mathrm{V}_{5 \%}, \mathrm{~V}_{10 \%}$, $\mathrm{V}_{25 \%}, \mathrm{~V}_{50 \%}, \mathrm{~V}_{75 \%}, \mathrm{~V}_{90 \%}, \mathrm{~V}_{100 \%}, \mathrm{~V}_{125 \%}(\mathrm{Vx} \%$ was the volume receiving at least $x \%$ of the dose), $D_{\max }$ (maximum dose), $\mathrm{D}_{0.01 \mathrm{cc},}, \mathrm{D}_{0.1 \mathrm{cc} c^{\prime}}, \mathrm{D}_{1 \mathrm{cc},}, \mathrm{D}_{2 \mathrm{cc} c^{\prime}}, \mathrm{D}_{5 \mathrm{cc} c^{\prime}}, \mathrm{D}_{10 \mathrm{cc} \mathrm{c}^{\prime}}, \mathrm{D}_{20 \mathrm{cc}}$, and $\mathrm{D}_{50 \mathrm{cc}}\left(\mathrm{D}_{\mathrm{xcc}}\right.$ was the dose to most exposed $\mathrm{x} \mathrm{cm}^{3}$ ) were recorded and compared in both sessions. The effect of rectal volume on DVH was assessed in each fraction.

Inclusion criteria for this study were the age of 18 years and higher with the ability to provide informed

Table 1. Patients' characteristics and study's variables

\begin{tabular}{|c|c|}
\hline Patient-related factors & Mean \pm SD \\
\hline \multicolumn{2}{|l|}{ Age } \\
\hline All patients & $57.5 \pm 1.05$ \\
\hline Endometrial cancers & $58.72 \pm 1.00$ \\
\hline Cervical cancers & $44.00 \pm 5.65$ \\
\hline Disease and treatment-related factors & Frequency (\%) \\
\hline \multicolumn{2}{|l|}{ Site } \\
\hline Endometrium & $22(91.7)$ \\
\hline Cervix & $2(8.3)$ \\
\hline \multicolumn{2}{|l|}{ Stage } \\
\hline IA & $8(33.3)$ \\
\hline $\mathrm{IB}^{*}$ & $9(37.5)$ \\
\hline II & $4(16.6)$ \\
\hline III & $3(12.5)$ \\
\hline \multicolumn{2}{|l|}{ Histology } \\
\hline Endometrial adenocarcinoma & $22(91.7)$ \\
\hline Cervical adenocarcinoma & $1(4.16)$ \\
\hline Cervical SCC & $1(4.16)$ \\
\hline \multicolumn{2}{|l|}{ EBRT } \\
\hline Yes & $15(62.5)$ \\
\hline No & $9(37.5)$ \\
\hline \multicolumn{2}{|l|}{ Chemotherapy } \\
\hline Yes & $6(25)$ \\
\hline No & $18(75)$ \\
\hline \multicolumn{2}{|l|}{ EBRT dose } \\
\hline 45 Gy & $11(45.83)$ \\
\hline 50.4 Gy & $4(16.6)$ \\
\hline \multicolumn{2}{|l|}{ BT dose } \\
\hline 15 Gy & $15(62.5)$ \\
\hline 30 Gy & $9(37.5)$ \\
\hline
\end{tabular}

*Including 2 cases of stage IBI cervical cancer, SD - standard deviation, SCC - squamous cell carcinoma, EBRT - external beam radiotherapy, Gy - Gray, $B T$ - brachytherapy consent, biopsy-proven uterine or cervical cancer, and hysterectomy before brachytherapy. Exclusion criteria were the age under 18 years, weight over $100 \mathrm{~kg}$ with restriction to undergone MRI, history of sensitivity to rifaximin and rifamycin antibiotics, and diarrhea associated with fever.

\section{Statistical analysis}

In this prospective interventional (semi-experimental) study, based on results from previous studies (especially results from a research of Andres et al.), we determined a sample size of 24 patients by using equation for calculating sample size in unlimited population, taking into account a margin error of $5 \%$.

After data collection, the patients and their tumor characteristics, including age, location and type of cancer, and disease stage based on FIGO 2009 staging system were analyzed, and rectal volume and DVH parameters in two sessions of brachytherapy without and with rifaximin were examined. Tables and statistical graphs were used to demonstrate the results as frequency and frequency's percentage in qualitative data and as mean ( \pm standard deviation) or median (interquartile range) for non-normal quantitative data. Normality was assessed with Shapiro-Wilk test and compared with paired $t$-test and Wilcoxon signed rank-test for unpaired and paired data, respectively. Data correlations were analyzed with Spearman's rank correlation test. The threshold for significance of outcomes was considered as $p$-value $<0.05$. All analyses were performed using SPSS software version 22 .

\section{Results}

From September 2019 to March 2020, 24 consecutive patients with cervical and endometrial cancers were recruited from those referred for adjuvant HDR brachytherapy. Patients' characteristics and disease-related factors are presented in Table 1 . Fifteen patients $(62.5 \%)$ received pelvic radiotherapy and 6 patients $(25 \%)$ were treated with concurrent chemotherapy. External radiotherapy dose was applied as 45 to 50.4 Gy in 25 to 28 fractions. Brachytherapy dose was used as 15 Gy in 3 sessions, or 30 Gy in 6 sessions with or without external radiotherapy, respectively (Table 1 ).

Rectal volume was $59.5 \mathrm{cc}$ (range, 48.7-73.5 cc) and $63.5 \mathrm{cc}$ (range, 55.5-79 cc) in sessions with and without rifaximin, respectively. Rifaximin reduced rectal volume by $6.44 \%$, which was statistically significant ( $p$-value $=0.01$ ). There were no statistically significant correlations between rifaximin use and $\mathrm{V}_{5 \%}, \mathrm{~V}_{10 \%}, \mathrm{~V}_{25 \%}, \mathrm{~V}_{50 \%}, \mathrm{~V}_{75 \%}, \mathrm{~V}_{90 \%}$, $\mathrm{V}_{100 \%}$, and $\mathrm{V}_{125 \%}$ (all $p$-values $>0.05$ ). $\mathrm{D}_{\max }$ was $94.9 \mathrm{~Gy}$ (range, 88.6-103 Gy) and 95.7 Gy (range, 87.3-101 Gy) in sessions with and without rifaximin, respectively, with no statistically significant difference $(p$-value $=0.717$ ) There were no statistically significant correlations between rifaximin use and $\mathrm{D}_{0.01 \mathrm{c} c^{\prime}} \mathrm{D}_{0.1 \mathrm{cc} \mathrm{c}^{\prime}} \mathrm{D}_{1 \mathrm{cc}}, \mathrm{D}_{2 \mathrm{cc}}$ and $\mathrm{D}_{5 \mathrm{cc}}$ (all $p$-values $>0.05$ ) (Table 2).

Spearman's rank correlation test showed that there was no statistically significant correlation between rectal volume and DVH parameters (all $p$-values $>0.05$ ). Rectal 
Table 2. Rectal dose-volume parameters in both groups of patients with and without rifaximin use

\begin{tabular}{|c|c|c|c|c|c|c|c|}
\hline \multirow[t]{2}{*}{ Parameter } & \multicolumn{3}{|c|}{ Rifaximin group } & \multicolumn{3}{|c|}{ Non-rifaximin group } & \multirow[b]{2}{*}{$p$-value } \\
\hline & Median & 25 PCTL & 75 PCTL & Median & 25 PCTL & 75 PCTL & \\
\hline Rectal volume (cc) & 59.5 & 48.7 & 73.5 & 63.6 & 55.5 & 79 & 0.011 \\
\hline $\mathrm{V}_{5 \%}(\%)$ & 100.0 & 100.0 & 100.0 & 100.0 & 100.0 & 100.0 & 0.836 \\
\hline$V_{10 \%}(\%)$ & 100.0 & 99.8 & 100.0 & 100.0 & 99.7 & 100.0 & 0.500 \\
\hline$V_{25 \%}(\%)$ & 71.6 & 65.1 & 82.3 & 69.0 & 57.8 & 75.9 & 0.959 \\
\hline$V_{50 \%}(\%)$ & 33.6 & 25.6 & 42.2 & 31.0 & 22.2 & 38.0 & 0.837 \\
\hline$V_{75 \%}(\%)$ & 14.1 & 9.22 & 18.0 & 13.2 & 7.63 & 19.1 & 0.721 \\
\hline$V_{90 \%}(\%)$ & 6.75 & 3.82 & 8.65 & 6.55 & 3.3 & 9.98 & 0.998 \\
\hline$V_{100 \%}(\%)$ & 3.3 & 1.67 & 4.7 & 2.8 & 1.67 & 6.2 & 0.412 \\
\hline$V_{125 \%}(\%)$ & 0.2 & 0.0 & 0.4 & 0.15 & 0.0 & 0.425 & 0.669 \\
\hline$D_{\max }(G y)$ & 94.9 & 88.6 & 103 & 95.7 & 87.3 & 101 & 0.717 \\
\hline $\mathrm{D}_{0.01 c c}(\mathrm{~Gy})$ & 133 & 124 & 144 & 134 & 122 & 141 & 0.716 \\
\hline $\mathrm{D}_{0.1 \mathrm{cc}}(\mathrm{Gy})$ & 127 & 118 & 133 & 127 & 116 & 133 & 0.596 \\
\hline$D_{1 c c}(G y)$ & 108 & 102 & 115 & 111 & 101 & 114 & 0.215 \\
\hline$D_{2 c c}(G y)$ & 101 & 94.6 & 106 & 103 & 93.4 & 107 & 0.147 \\
\hline$D_{5 c c}(G y)$ & 88.6 & 81.4 & 92.3 & 87.6 & 79.5 & 92.4 & 0.210 \\
\hline
\end{tabular}

$P C T L$ - percentile, Gy -Gray, $V x \%$ - volume receiving at least $x \%$ of the dose, $D_{\text {max }}$ - maximum dose, Dx cc-dose to most exposed $x \mathrm{~cm}^{3}$

volume reduction was correlated with an increase in all volume parameters, which was not statistically significant. Rectal volume reduction was correlated with an increase in $\mathrm{D}_{\max }, \mathrm{D}_{0.01 \mathrm{c} c^{\prime}}, \mathrm{D}_{1 \mathrm{c} c^{\prime}}, \mathrm{D}_{2 \mathrm{cc}}$ and a decrease in $\mathrm{D}_{0.1 \mathrm{cc}}$ and $\mathrm{D}_{5 \mathrm{cc}}$, respectively, which was not statistically significant (Tables 3, 4, and Figures 1, 2).

\section{Discussion}

In our study, rifaximin consumption reduced rectal volume. This is likely to be achieved by suppressing intestinal bacteria and reducing $\mathrm{H}_{2}$ gas production, as shown in previous studies by Pimentel et al. [23], Lauritano et al. [24], and Di Stefano et al. [25].

In a study by Sheybani et al. [13] with 21 locally advanced cervical cancer patients who received definitive chemoradiation therapy with brachytherapy boost using tandem and ovoid, the effect of bladder and rectal filling on dose-volume parameters was investigated, and the results of this study showed that there was a direct and significant correlation between rectal volume and $\mathrm{V}_{50 \%}$ ( $p$-value $<0.0001)$ and $\mathrm{V}_{74 \%}(p$-value $<0.0001)$, which was not in line with our research. A study by Lim et al. [14] on 51 patients with locally advanced cervical cancer who received definitive chemoradiation therapy with HDR brachytherapy boost using tandem and ovoid, the impact of rectal distention and tandem angle on rectal dose was investigated. It was found that an increase of rectal volume significantly increased $D_{2 c c}(p$-value $=0.016)$, and it was not consistent with our research

In 2016, Sabater et al. [18] examined the effect of rectal enema in HDR brachytherapy of vaginal cuff after surgery. In their study, rectal volume was generally reduced by $15 \%$ with the use of enema, and it was statistically significant $(p=0.0018)$. There were no statistically significant correlations between rectal volume and DVH parameters, which was consistent with our study. Another study by Sabater et al. from 2015 [19] showed a statistically significant positive correlation between rectal volume and $D_{\max }$ $\mathrm{D}_{0.1 \mathrm{cc}}, \mathrm{D}_{1 \mathrm{cc}}$, and $\mathrm{D}_{2 \mathrm{cc}}$ parameters. A study by Siavashpour et al. [20] found that the increase of rectal volume significantly increased $\mathrm{D}_{0.1 \mathrm{cc}}$ and $\mathrm{D}_{2 \mathrm{cc}}$ and decreased $\mathrm{D}_{10 \mathrm{cc}}$ $\mathrm{D}_{30 \mathrm{cc}}$, and $\mathrm{D}_{50 \mathrm{cc}}$ parameters, which was not in line with the present research.

In a study by Andres et al. [21] on 20 cervical cancer patients treated with external radiation therapy, with a sequence like in our study, first brachytherapy session was performed as a basis and second session was performed after using rectal enema. There was no statistically significant correlation between the rectal enema and rectal volume or DVH parameters, which was in line with our study.

In our research, there was no statistically significant correlation between rifaximin use and rectal DVH parameters, especially $\mathrm{D}_{2 \mathrm{cc}}(p$-value $=0.599)$. We did not find a study, in which the association of rifaximin with rectal DVH parameters was directly measured. However, since in our study, rifaximin was significantly associated with a reduction in rectal volume and according to Lim et al. [14], Sabater et al. [19], and Siavashpour et al. [20], it could be expected that the use of rifaximin may have a significant correlation with rectal DVH parameters. This finding was predictable in two studies, i.e., Andres et al. [21] and Sabater et al. [18], in which there was no significant difference between DVH parameters and rectal volume. However, the impact of rectal filling on DVH parameters could be different between brachytherapy in an adjuvant setting and brachytherapy in a definitive setting, due to differences in geometry and different applicators. It should be considered that the differences between intes- 
Table 3. Spearman's rank correlation matrix of rectal volume with DVH parameters (percentage)

\begin{tabular}{|c|c|c|c|c|c|c|c|c|c|c|}
\hline Parameter & & Vol. & $V_{5 \%}$ & $\mathrm{~V}_{10 \%}$ & $\mathrm{~V}_{25 \%}$ & $V_{50 \%}$ & $V_{75 \%}$ & $V_{90 \%}$ & $\mathrm{~V}_{100 \%}$ & $\mathrm{~V}_{125 \%}$ \\
\hline Vol. & $\begin{array}{l}\text { Pearson's } r \\
p \text {-value } \\
\text { Spearman's rho } \\
p \text {-value }\end{array}$ & $\begin{array}{l}- \\
- \\
- \\
-\end{array}$ & & & & & & & & \\
\hline$V_{5 \%}$ & $\begin{array}{l}\text { Pearson's } r \\
p \text {-value } \\
\text { Spearman's rho } \\
p \text {-value }\end{array}$ & $\begin{array}{c}-0.320 \\
0.987 \\
-0.216 \\
0.930\end{array}$ & $\begin{array}{l}- \\
- \\
- \\
-\end{array}$ & & & & & & & \\
\hline$V_{10 \%}$ & $\begin{array}{l}\text { Pearson's } r \\
p \text {-value } \\
\text { Spearman's rho } \\
p \text {-value }\end{array}$ & $\begin{array}{c}-0.530 \\
1.000 \\
-0.384 \\
0.996\end{array}$ & $\begin{array}{c}0.785^{\star * \star} \\
<0.001 \\
0.301^{\star} \\
0.019\end{array}$ & $\begin{array}{l}- \\
- \\
- \\
-\end{array}$ & & & & & & \\
\hline$V_{25 \%}$ & $\begin{array}{l}\text { Pearson's } r \\
p \text {-value } \\
\text { Spearman's rho } \\
p \text {-value }\end{array}$ & $\begin{array}{c}-0.612 \\
1.000 \\
-0.471 \\
1.000 \\
\end{array}$ & $\begin{array}{c}0.443^{* * *} \\
<0.001 \\
0.247^{\star} \\
0.045\end{array}$ & $\begin{array}{c}0.770^{\star * *} \\
<0.001 \\
0.702^{*} \\
<0.001 \\
\end{array}$ & $\begin{array}{l}- \\
- \\
- \\
-\end{array}$ & & & & & \\
\hline$V_{50 \%}$ & $\begin{array}{l}\text { Pearson's } r \\
p \text {-value } \\
\text { Spearman's rho } \\
p \text {-value }\end{array}$ & $\begin{array}{c}-0.650 \\
1.000 \\
-0.654 \\
1.000 \\
\end{array}$ & $\begin{array}{c}0.317^{\star} \\
0.14 \\
0.247^{\star} \\
0.045\end{array}$ & $\begin{array}{l}0.575^{\star * \star} \\
<0.001 \\
0.605^{\star * \star} \\
<0.001\end{array}$ & $\begin{array}{l}0.849^{* * *} \\
<0.001 \\
0.854^{* * *} \\
<0.001\end{array}$ & $\begin{array}{l}- \\
- \\
- \\
-\end{array}$ & & & & \\
\hline$V_{75 \%}$ & $\begin{array}{l}\text { Pearson's } r \\
p \text {-value } \\
\text { Spearman's rho } \\
p \text {-value }\end{array}$ & $\begin{array}{c}-0.564 \\
1.000 \\
-0.619 \\
1.000 \\
\end{array}$ & $\begin{array}{l}0.243^{\star} \\
0.048 \\
0.247^{\star} \\
0.045\end{array}$ & $\begin{array}{l}0.430^{\star \star} \\
<0.001 \\
0.511^{\star \star \star} \\
<0.001\end{array}$ & $\begin{array}{l}0.594^{\star \star *} \\
<0.001 \\
0.645^{\star \star *} \\
<0.001\end{array}$ & $\begin{array}{c}0.887^{\star \star *} \\
<0.001 \\
0.904^{\star * \star} \\
<0.001\end{array}$ & $\begin{array}{l}- \\
- \\
- \\
-\end{array}$ & & & \\
\hline$V_{90 \%}$ & $\begin{array}{l}\text { Pearson's } r \\
p \text {-value } \\
\text { Spearman's rho } \\
p \text {-value }\end{array}$ & $\begin{array}{c}-0.482 \\
1.000 \\
-0.541 \\
1.000 \\
\end{array}$ & $\begin{array}{l}0.207 \\
0.079 \\
0.237 \\
0.052 \\
\end{array}$ & $\begin{array}{c}0.357^{\star \star} \\
0.006 \\
0.441^{\star \star \star} \\
<0.001 \\
\end{array}$ & $\begin{array}{c}0.445^{\star \star \star} \\
<0.001 \\
0.540^{\star \star \star} \\
<0.001\end{array}$ & $\begin{array}{c}0.754^{\star \star \star} \\
<0.001 \\
0.822 \\
<0.001 \\
\end{array}$ & $\begin{array}{l}0.969^{\star \star \star} \\
<0.001 \\
0.974^{\star \star \star} \\
<0.001 \\
\end{array}$ & $\begin{array}{l}- \\
- \\
- \\
-\end{array}$ & & \\
\hline$V_{100 \%}$ & $\begin{array}{l}\text { Pearson's } r \\
p \text {-value } \\
\text { Spearman's rho } \\
p \text {-value }\end{array}$ & $\begin{array}{c}-0.425 \\
0.999 \\
-0.499 \\
1.000 \\
\end{array}$ & $\begin{array}{c}0.179 \\
0.112 \\
0.247^{\star} \\
0.045 \\
\end{array}$ & $\begin{array}{c}0.293^{*} \\
0.022 \\
0.331^{\star} \\
0.011 \\
\end{array}$ & $\begin{array}{c}0.327^{\star} \\
0.012 \\
0.414^{\star *} \\
0.002 \\
\end{array}$ & 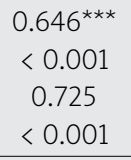 & $\begin{array}{l}0.919^{\star \star \star} \\
<0.001 \\
0.921^{\star \star \star} \\
<0.001 \\
\end{array}$ & $\begin{array}{l}0.981^{\star \star \star} \\
<0.001 \\
0.972^{\star \star \star} \\
<0.001 \\
\end{array}$ & $\begin{array}{l}- \\
- \\
- \\
-\end{array}$ & \\
\hline $\mathrm{V}_{125 \%}$ & $\begin{array}{l}\text { Pearson's } r \\
p \text {-value } \\
\text { Spearman's rho } \\
p \text {-value }\end{array}$ & $\begin{array}{c}-0.266 \\
0.966 \\
-0.267 \\
0.967\end{array}$ & $\begin{array}{l}0.088 \\
0.276 \\
0.158 \\
0.142\end{array}$ & $\begin{array}{l}0.159 \\
0.140 \\
0.158 \\
0.142\end{array}$ & $\begin{array}{l}0.116 \\
0.216 \\
0.212 \\
0.074\end{array}$ & $\begin{array}{c}0.376^{\star * \star} \\
0.004 \\
0.500^{\star * \star} \\
<0.001\end{array}$ & $\begin{array}{l}0.680^{\star * *} \\
<0.001 \\
0.714^{\star \star \star} \\
<0.001\end{array}$ & $\begin{array}{l}0.805^{\star * *} \\
<0.001 \\
0.813^{\star * *} \\
<0.001\end{array}$ & $\begin{array}{l}0.878^{\star * *} \\
<0.001 \\
0.880^{\star * *} \\
<0.001\end{array}$ & $\begin{array}{l}- \\
- \\
- \\
-\end{array}$ \\
\hline
\end{tabular}
DVH - dose-volume histogram, Vol. - rectal volume, $v x \%$ - volume receiving at least $x \%$ of the dose

Table 4. Spearman's rank correlation matrix of rectal volume with DVH parameters (Gray)

\begin{tabular}{|c|c|c|c|c|c|c|c|c|}
\hline Parameter & & Vol. & $D_{\max }$ & $\mathrm{D}_{0.01 \mathrm{cc}}$ & $\mathrm{D}_{0.1 \mathrm{cc}}$ & $\mathrm{D}_{1 \mathrm{cc}}$ & $D_{2 c c}$ & $\mathrm{D}_{5 \mathrm{cc}}$ \\
\hline Vol. & $\begin{array}{l}\text { Spearman's rho } \\
p \text {-value }\end{array}$ & $\begin{array}{l}- \\
-\end{array}$ & & & & & & \\
\hline $\mathrm{D}_{\max }$ & $\begin{array}{l}\text { Spearman's rho } \\
p \text {-value }\end{array}$ & $\begin{array}{c}-0.202 \\
0.916\end{array}$ & - & & & & & \\
\hline $\mathrm{D}_{0.01 c c}$ & $\begin{array}{l}\text { Spearman's rho } \\
p \text {-value }\end{array}$ & $\begin{array}{c}-0.202 \\
0.915\end{array}$ & $\begin{array}{l}1.000^{* * *} \\
<0.001\end{array}$ & - & & & & \\
\hline $\mathrm{D}_{0.1 \mathrm{cc}}$ & $\begin{array}{l}\text { Spearman's rho } \\
p \text {-value }\end{array}$ & $\begin{array}{l}0.024 \\
0.435\end{array}$ & $\begin{array}{l}0.922^{\star * *} \\
<0.001\end{array}$ & $\begin{array}{l}0.921^{\star * *} \\
<0.001\end{array}$ & $\begin{array}{l}- \\
-\end{array}$ & & & \\
\hline$D_{1 c c}$ & $\begin{array}{l}\text { Spearman's rho } \\
p \text {-value }\end{array}$ & $\begin{array}{c}-0.068 \\
0.676\end{array}$ & $\begin{array}{l}0.888^{* * *} \\
<0.001\end{array}$ & $\begin{array}{l}0.887^{\star \star *} \\
<0.001\end{array}$ & $\begin{array}{l}0.900^{* * *} \\
<0.001\end{array}$ & $\begin{array}{l}- \\
-\end{array}$ & & \\
\hline$D_{2 c c}$ & $\begin{array}{l}\text { Spearman's rho } \\
p \text {-value }\end{array}$ & $\begin{array}{c}-0.037 \\
0.599\end{array}$ & $\begin{array}{l}0.862^{\star \star \star} \\
<0.001\end{array}$ & $\begin{array}{l}0.862^{\star \star \star} \\
<0.001\end{array}$ & $\begin{array}{l}0.893^{* * *} \\
<0.001\end{array}$ & $\begin{array}{l}0.987^{\star * \star} \\
<0.001\end{array}$ & $\begin{array}{l}- \\
-\end{array}$ & \\
\hline$D_{5 c c}$ & $\begin{array}{l}\text { Spearman's rho } \\
\text { p-value }\end{array}$ & $\begin{array}{l}0.075 \\
0.306\end{array}$ & $\begin{array}{l}0.810^{\star \star \star} \\
<0.001\end{array}$ & $\begin{array}{l}0.810^{\star \star \star} \\
<0.001\end{array}$ & $\begin{array}{l}0.865^{\star \star \star} \\
<0.001\end{array}$ & $\begin{array}{l}0.926^{\star \star \star} \\
<0.001\end{array}$ & $\begin{array}{l}0.964^{\star \star \star} \\
<0.001\end{array}$ & $\begin{array}{l}- \\
-\end{array}$ \\
\hline
\end{tabular}

$D V H$-dose-volume histogram, Vol. - rectal volume, $D_{\max }-$ maximum dose, $D_{x c c}$-dose to most exposed $x \mathrm{~cm}^{3}$ 


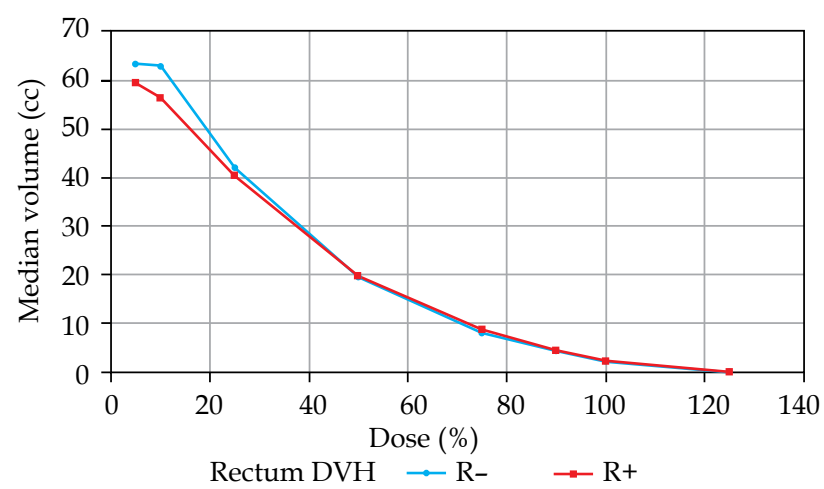

Fig. 1. Rectal dosimetric changes with median rectal volume (cc) in both groups

$D V H$ - dose-volume histogram, $R--$ group without rifaximin, $R+-$ group with rifaximin

tinal microbiota in various patients may have an impact on the rifaximin effect to reduce bowel gas production and rectal filling. Conversely, the impact of rifaximin on intestinal microbiota could change the efficacy and tolerance to irradiation.

\section{Conclusions}

Although the addition of rifaximin to bowel preparation significantly reduced rectal volume, this reduction was not excessive $(6.44 \%)$. This small, but statistically significant impact on rectal volume is unlikely to be clinically relevant, especially in the adjuvant setting. The absence of correlation between rectal DVH parameters and rectal volume reduction may be due to paucity of rectal volume change. Since no significant difference was observed in rectal DVH parameters, it is recommended that brachytherapy should be performed without the use of rifaximin, until further researches validate its effects. Given that in some studies investigating other methods of reducing rectal volume, such as enema and intestinal preparations, where the reduction of rectal volume has not been significantly associated with DVH parameters, it is possible that changes in rectal volume are not related to DVH parameters. Another possibility is that the effect of rifaximin alone is not much different from the effect of other methods of reducing rectal volume. Therefore, it is recommended that other studies should be performed to compare the effect of rifaximin alone versus other methods, to investigate the impact of changing microbiota, and to evaluate clinical endpoints, such as treatment-related toxicities and survival.

\section{Acknowledgments}

This article was retrieved from residency thesis of Ahvaz Jundishapur University of Medical Sciences (CRC9819), and the authors declare no conflict of interest.

\section{Disclosure}

The authors report no conflict of interest.

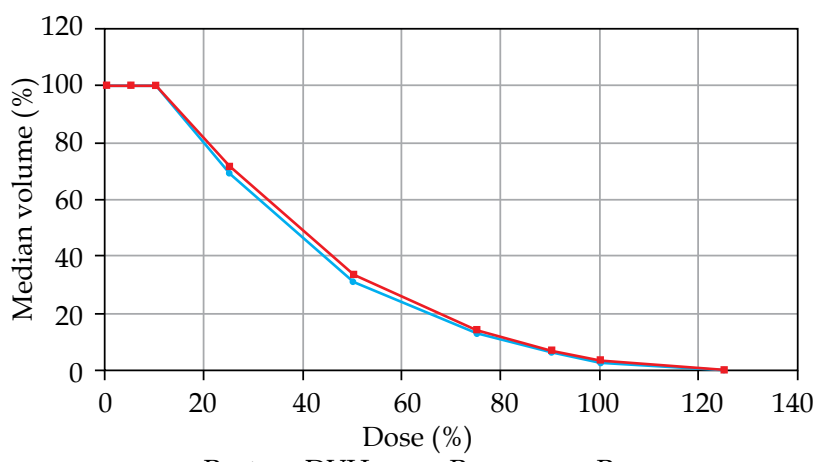

Rectum DVH $\rightarrow \mathrm{R}-\quad \rightarrow \mathrm{R}+$

Fig. 2. Rectal dosimetric changes with median rectal volume (percentage) in both groups

$D V H$ - dose-volume histogram, $R--$ group without rifaximin, $R+-$ group with rifaximin

\section{References}

1. Amant F, Mirza MR, Koskas M, Creutzberg CL. Cancer of the corpus uteri. Int J Gynaecol Obstet 2015; 131 (Suppl 2): S96-S104.

2. Morice P, Leary A, Creutzberg C, Abu-Rustum N et al. Endometrial cancer. Lancet 2016; 387: 1094-1108.

3. Hosseini SM, Arvandi SH, Shahbazian H et al. Comparing endometrial cancer in women younger and older than 40 years referred to radiotherapy-oncology department of Ahwaz Golestan Hospital from 2001-2012. Jundishapur Sci Med J 2014; 13: 437-444.

4. Siegel RL, Miller KD, Jemal A. Cancer statistics, 2018. CA Cancer J Clin 2018; 68: 7-30.

5. Global Burden of Disease Cancer Collaboration. Global, regional, and national cancer incidence, mortality, years of life lost, years lived with disability, and disability-adjusted lifeyears for 29 cancer groups, 1990 to 2017: a systematic analysis for the global burden of disease study. JAMA Oncology 2019; 5: 1749-1768.

6. Small Jr W, Beriwal S, Demanes DJ et al. American Brachytherapy Society consensus guidelines for adjuvant vaginal cuff brachytherapy after hysterectomy. Brachytherapy 2012; 11: 58-67.

7. Ujaimi R, Milosevic M, Fyles A et al. Intermediate dose-volume parameters and the development of late rectal toxicity after MRI-guided brachytherapy for locally advanced cervix cancer. Brachytherapy 2017; 16: 968-975.

8. Zhou YC, Zhao LN, Wang $\mathrm{N}$ et al. Late rectal toxicity determined by dose-volume parameters in computed tomography-based brachytherapy for locally advanced cervical cancer. Cancer Med-Us 2016; 5: 434-441.

9. Kato S, Linh TDN, Ohno T et al. CT-based 3D dose-volume parameter of the rectum and late rectal complication in patients with cervical cancer treated with high-dose-rate intracavitary brachytherapy. J Radiat Res 2010; 51: 215-221.

10. Hung J, Shen S, Jennifer F, Kim RY. Image-based 3D treatment planning for vaginal cylinder brachytherapy: dosimetric effects of bladder filling on organs at risk. Int J Radiat Oncol 2012; 83: 980-985.

11. Otón LF, Dolado MC, Núñez EJ, Otón CA. Effect of constipation on dosimetry after permanent seed brachytherapy for prostate cancer. J Contemp Brachytherapy 2015; 7: 247-251.

12. Holloway CL, Macklin EA, Cormack RA, Viswanathan AN. Should the organs at risk be contoured in vaginal cuff brachytherapy? Brachytherapy 2011; 10: 313-317. 
13. Sheybani A, Tennapel MJ, Sun W, Kim Y et al. Dose-volume effect of bladder and rectal filling during intracavitary highdose-rate brachytherapy. Brachytherapy 2013; 12: S27.

14. Lim J, Durbin-Johnson B, Valicenti R et al. The impact of maximum rectal distention and tandem angle on rectal dose delivered in $3 \mathrm{~d}$ planned gynecologic high dose-rate brachytherapy. Int J Gynecol Cancer 2013; 23: 1078-1083.

15. Sabater S, Sevillano MM, Andres I et al. Reduction of rectal doses by removal of gas in the rectum during vaginal cuff brachytherapy. Strahlenther Onkol 2013; 189: 951-956.

16. Sabater S, Arenas M, Berenguer R et al. Dosimetric analysis of rectal filling on rectal doses during vaginal cuff brachytherapy. Brachytherapy 2015; 14: 458-463.

17. Yahya S, Zarkar A, Southgate E et al. Which bowel preparation is best? Comparison of a high-fibre diet leaflet, daily microenema and no preparation in prostate cancer patients treated with radical radiotherapy to assess the effect on planned target volume shifts due to rectal distension. $\mathrm{Br}$ J Radiol 2013; 86: 20130457.

18. Sabater S, Andrés I, Gascon M et al. Effect of rectal enemas on rectal dosimetric parameters during high-dose-rate vaginal cuff brachytherapy. Strahlenther Onkol 2016; 192: 248-253.

19. Sabater S, Andres I, Jimenez-Jimenez E et al. Rectal contrast increases rectal dose during vaginal cuff brachytherapy. Brachytherapy 2016; 15: 35-39.

20. Siavashpour Z, Aghamiri MR, Jaberi R et al. Optimum organ volume ranges for organs at risk dose in cervical cancer intracavitary brachytherapy. J Contemp Brachytherapy 2016; 8: 135-142.

21. Andres I, Gutierrez-Perez M, Rodriguez-Vela MP et al. The usefulness of fleet rectal enemas on high-dose-rate intracavitary cervical cancer brachytherapy. A prospective trial. J Contemp Brachytherapy 2017; 9: 224-229.

22. Hosni A, Rosewall T, Craig T et al. The effect of bowel preparation regime on interfraction rectal filling variation during image guided radiotherapy for prostate cancer. Radiat Oncol 2017; 12: 50.

23. Pimentel M, Lembo A, Chey WD et al. Rifaximin therapy for patients with irritable bowel syndrome without constipation. N Engl J Med 2011; 364: 22-32.

24. Lauritano E, Gabrielli M, Scarpellini E, Ojetti V et al. Antibiotic therapy in small intestinal bacterial overgrowth: rifaximin versus metronidazole. Eur Rev Med Pharmacol Sci 2009; 13: 111-116.

25. Di Stefano M, Strocchi A, Malservisi S et al. Non-absorbable antibiotics for managing intestinal gas production and gas-related symptoms. Aliment Pharmacol Ther 2000; 14: 10011008.

26. Debbia EA, Maioli E, Roveta S, Marchese A. Effects of rifaximin on bacterial virulence mechanisms at supra- and subinhibitory concentrations. J Chemother 2008; 20: 186-194.

27. Pimentel M, Chow EJ, Lin HC. Normalization of lactulose breath testing correlates with symptom improvement in irritable bowel syndrome: a double-blind, randomized, placebo-controlled study. Am J Gastroenterol 2003; 98: 412-419.

28. Jiang ZD, DuPont HL. Rifaximin: in vitro and in vivo antibacterial activity - a review. Chemotherapy 2005; 51 Suppl: 67-72.

29. Gerard L, Garey KW, DuPont HL. Rifaximin, a nonabsorbable rifamycin antibiotic for use in nonsystemic gastrointestinal infections. Expert Rev Anti Infect Ther 2005; 3: 201-211. 